\title{
Paste-Type Negative Plate for Alkaline Storage Batteries One Example of Random Combination Method
}

\author{
Akira Sono*
}

Experimental design by the modern statistics especially orthogonal layout is widely applied in various fields in these days, but few of these(1) results have been published.

The author has attempted to ascertain whether this method is available or not in the field of his interest by applying this method in the maturing of negative plate of alkaline storage battery.

As the experiment has been designed for 17 factors in 3 levels a simple orthogonal layout $L_{27}\left(3^{13}\right)$ for 13 factors does not suffice. Therefore, the two-step random combination method ${ }^{(2)}$ which can further accomodate several tests for interaction besides 17 factors in 3 levels by 27 samples was adopted. In principle, it is a random combination of the two sets of $\mathrm{L}_{27}\left(3^{13}\right)$, the analysis of variance being done at first independently in each set, and by modifying the effects of the larger factors of the set, then the variations of the other set recalculated. By repeating such recalculations mutually between the two sets in sequence, the errors converged to constant values and the whole factors separated.

The details of the processes and factors referred to are shown in Tables 1 and 2 . The sample plates were made in a size of about $40 \times 15 \times$ $2 \mathrm{~mm}$ and each contained about $1.7 \mathrm{~g}$ of CdO. Initial capacity and durability

Table 1 Preparing Process of Paste-type Negative Plate.

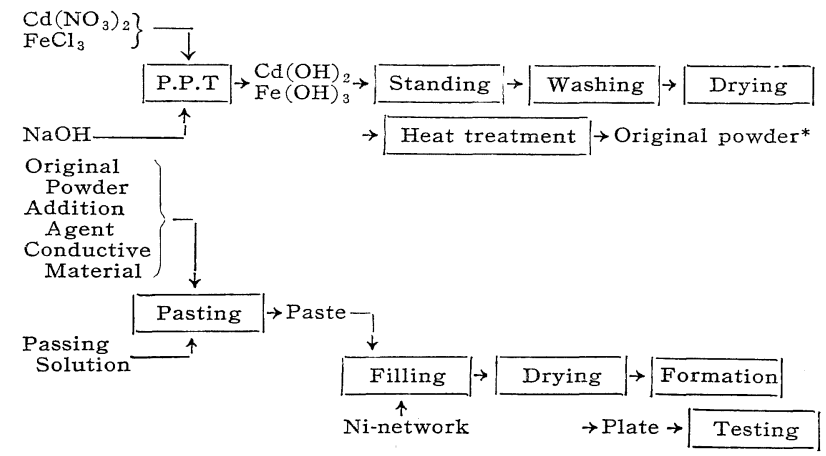

Table 2 The Factors and Their Conditions.

(A) 1 st Part of Processes.

\begin{tabular}{|c|c|c|c|c|c|c|}
\hline \multirow{2}{*}{\multicolumn{3}{|c|}{ Factor }} & \multicolumn{3}{|c|}{ Conditions } & \multirow{2}{*}{ Note } \\
\hline & & & 1 & 2 & 3 & \\
\hline \multicolumn{3}{|c|}{ Conc. of $\mathrm{Cd}\left(\mathrm{NO}_{3}\right)_{2}$ soln. } & 100 & 200 & 400 & $25 \mathrm{cc}$ of original soln*. was diluted to leave \\
\hline \multicolumn{3}{|c|}{ Vol. of $\mathrm{FeCl}_{3}$ soln. $\quad$ (cc) } & 20 & 15 & 10 & The vol. of original soln**. to be added \\
\hline \multirow{2}{*}{\multicolumn{2}{|c|}{$\begin{array}{l}\text { Shortage of } \mathrm{NaOH} \text { soln. } \\
\text { Conc. of } \dot{\mathrm{NaOH}} \text { soln. }\end{array}$}} & $(\mathrm{cc})$ & 0 & 1 & 2 & The vol. to be subtracted from the theoretical value. $\dagger$ \\
\hline & & $(\mathrm{cc})$ & 400 & 200 & 100 & The vol. obtained above was diluted to leave \\
\hline \multicolumn{2}{|c|}{ Temp. at precipitation } & $\left({ }^{\circ} \mathrm{C}\right)$ & 100 & 60 & 20 & $\pm 3^{\circ} \mathrm{C}$ \\
\hline \multirow{3}{*}{\multicolumn{2}{|c|}{$\begin{array}{l}\text { Time for standing } \\
\text { Number of washing } \\
\text { Temp. of heat treatment }\end{array}$}} & (h) & 0 & 4 & 24 & From precipitation to washing \\
\hline & & & 1 & 2 & 1 & Mother liquid was diluted to $1 l$. \\
\hline & & $\left({ }^{\circ} \mathrm{C}\right)$ & 700 & 600 & 500 & By siliconite furnace $\left( \pm 40^{\circ} \mathrm{C}\right)$ \\
\hline \multicolumn{3}{|c|}{ Time for " " (min.) } & long & mid. & short & Refer to the foot-note $\neq$ \\
\hline \multicolumn{7}{|c|}{$* 480 \mathrm{~g} \mathrm{Cd}^{*}\left(\mathrm{NO}_{3}\right)_{2} \cdot 4 \mathrm{H}_{2} \mathrm{O}$ per $11 \quad * * 235 \mathrm{~g} \mathrm{FeCl}_{3} \cdot 6 \mathrm{H}_{2} \mathrm{O}$ per $1 l$} \\
\hline \multicolumn{7}{|c|}{$\dagger 12.3 \mathrm{cc}$ of $\mathrm{NaOH}$ soln. $(418 \mathrm{~g} / l)$ for $20 \mathrm{cc}$ of original soln. of $\mathrm{FeCl}_{3}$} \\
\hline \multirow{2}{*}{\multicolumn{7}{|c|}{$\begin{array}{rll}11.0 & \text { " } \\
9.8 & \text { " }\end{array}$}} \\
\hline \multirow{5}{*}{$\ddagger$} & & & 10 & $"$ & & " \\
\hline & Temp. Time & Long & Middle & Sho & & \\
\hline & $700 \quad\left({ }^{\circ} \mathrm{C}\right)$ & 30 & 15 & & 7.5 & \\
\hline & 600 & 60 & 30 & & & \\
\hline & 500 & 120 & 60 & & & \\
\hline
\end{tabular}

* The Electrical Communication Laboratory, Nippon Telegraph and Telephone Public Corp., Musashino-shi, Tokyo The original written in Japanese can be seen in J. Electrochem. Soc. Japan, 26, 125 (1958). 
(B) 2 nd Part of Processes

\begin{tabular}{|c|c|c|c|c|}
\hline \multirow{2}{*}{ Factor } & \multicolumn{3}{|c|}{ Conditions } & \multirow{2}{*}{ Note } \\
\hline & 1 & 2 & 3 & \\
\hline Sort of addition agent & Asbestos* & Lignine** & $\mathrm{CdCO}_{3} \ddagger$ & $1 \%$ to original powder \\
\hline Sort of conductive material & Nickel $†$ & $\mathrm{HgO}_{+}^{+}$ & $\mathrm{A}-\mathrm{B} \oint$ & $10 \%$ \\
\hline Mesh of network & $(0.30 \mathrm{~mm} \phi)$ & $(0.35 \mathrm{~mm} \phi)$ & $\stackrel{10}{(m)}$ & woven with nickel wire $(40 \times 15 \mathrm{~mm})$ \\
\hline Sp. gr. of pasting soln. & 1.00 & 1.10 & 1.20 & $\mathrm{KOH}$ soln. \\
\hline Hardness of paste & medium & soft & hard & by hand. \\
\hline Temp. at drying plate $\left({ }^{\circ} \mathrm{C}\right)$ & 100 & 60 & 20 & $\pm 10^{\circ} \mathrm{C}$ \\
\hline Sp. gr. of forming soln. & 1.15 & 1.10 & 1.20 & $\begin{array}{l}\text { KOH soln. (the soln. was used also on } \\
\text { testing.) }\end{array}$ \\
\hline Current density at forming ( $\mathrm{A} / \mathrm{dm}^{2}$ ) & 0.10 & 0.40 & 0.20 & For both surfaces \\
\hline
\end{tabular}

* For Gooch crucible

** Sulfonate from waste soln. in puip production

Powder metal reduced from its oxide

$\ddagger$ Produced by ordinary method

§ Acetylene black

were tested with each of the test plates. Charge and discharge were carried out till 82 cycles, but as. most of the samples lost their active material by shedding before that time, the durability was compared with the capacity at the 32nd cycle. Analyses of variance were made on each kind of the tests and the effects of the factors with significant variance are shown in Fig. 1.
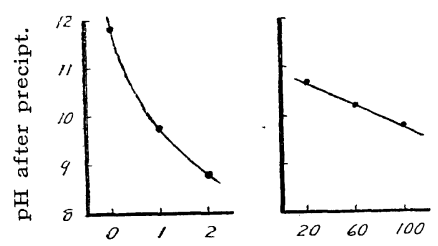
Shortage of $\mathrm{NaOH}$ Temp. at precipt.
$\left({ }^{\circ} \mathrm{C}\right)$
Fig. 1 (A) $\mathrm{PH}$ after precipitation.
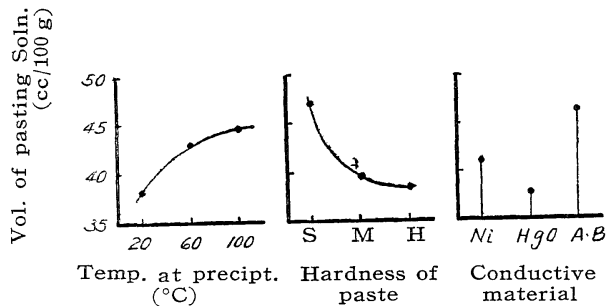

Fig. 1 (C) Volume of pasting solution.
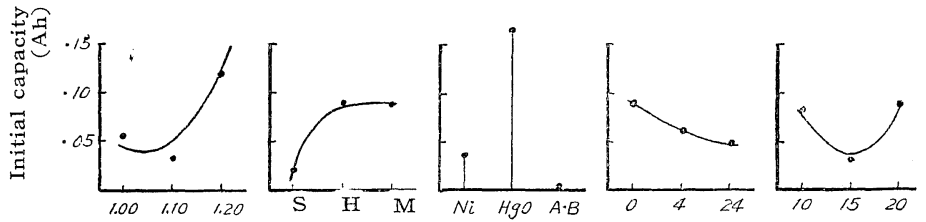

S: Soft

M: Medium

H : Hard

Sh: Short

Sp. Gr. of pasting Soln.

Hardness

Conductive material

Time for

standing $(\mathrm{h})$ added (cc)

L: Long
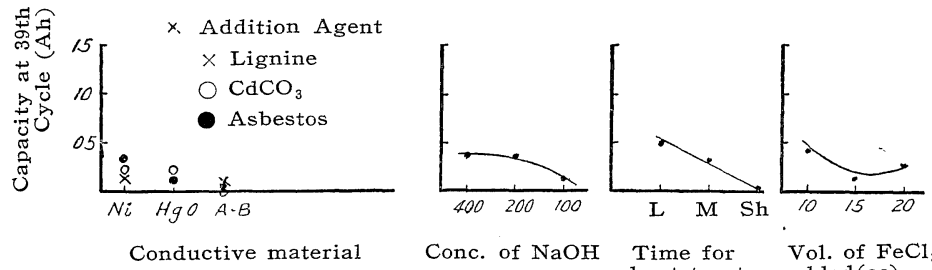

Conc. of $\mathrm{NaOH}$

Time for Vol. of $\mathrm{FeCl}_{3}$ heat treat. added (cc)

Fig. 1 (F) Durability evaluated by capacity at 32 nd charge and discharge cycle. 
The admixing of $\mathrm{HgO}$ as conducting material was useful because the reduced $\mathrm{Hg}$ in charged plate aided binding action of powder of active materials. Lignin was useful as anti-shrinkage agent of the active materials. The combination of $\mathrm{HgO}$ and lignin was much effective. Through these results, the optimum conditions for electrode plate were determined as shown in Table 3 and the samples of the same size as before were made. This time, the shedding of the active materials was prevented by covering the surface of the plate with saran fabrics and by pressing a net of nickel on it adequately. Thus, the shedding was prevented almost completely and the plates withstood over $2,5.00$ cycles of charge and discharge as shown in Fig. 2.

It has been recognized by this example that the orthogonal layout can detect the factor affecting large effect very efficiently out of many
Table 3 Most Suitable Procedure for Preparing of Paste-type Negative Plate.

\begin{tabular}{|c|c|c|c|c|}
\hline \multirow{2}{*}{ Process } & \multirow{2}{*}{ Factor } & \multirow{2}{*}{ Condition } & \multicolumn{2}{|c|}{ Its Effect on } \\
\hline & & & durability & $\begin{array}{c}\text { initial } \\
\text { capacity }\end{array}$ \\
\hline Precipt. & $\begin{array}{l}\text { Vol. of } \mathrm{FeCl}_{3} \\
\text { Conc. of } \mathrm{NaOH} \\
\text { Temperature }\end{array}$ & $\begin{array}{l}10 \mathrm{cc}(\mathrm{Cd}: \mathrm{Fe}=100: 11) \\
200 \sim 400 \mathrm{cc} \\
(12 \sim 21 \mathrm{gNaOH} / 1) \\
\text { below } 60^{\circ} \mathrm{C}\end{array}$ & * & $* *$ \\
\hline Standing & Time & soon after precipt. & & ? \\
\hline Washing & Number & 1 time & & \\
\hline $\begin{array}{l}\text { Heat } \\
\text { Treatment }\end{array}$ & $\begin{array}{l}\text { Temperature } \\
\text { Time }\end{array}$ & $\begin{array}{l}600^{\circ} \mathrm{C} \\
30 \sim 60 \mathrm{~min}\end{array}$ & $* *$ & \\
\hline Pasting & $\begin{array}{l}\text { Addition agent } \\
\text { Condct. material } \\
\text { Pasting soln. } \\
\text { Hardness of paste }\end{array}$ & $\begin{array}{l}\text { Lignine } \\
\mathrm{HgO} \\
\text { Sp. Gr. }=1.20 \mathrm{KOH} \\
\text { Med. or Hard }\end{array}$ & $\begin{array}{c}* \\
* *\end{array}$ & $\begin{array}{l}* * \\
* * \\
* *\end{array}$ \\
\hline Forming & Current density & $0.4 \mathrm{~A} / \mathrm{dm}^{2}$ & & \\
\hline
\end{tabular}

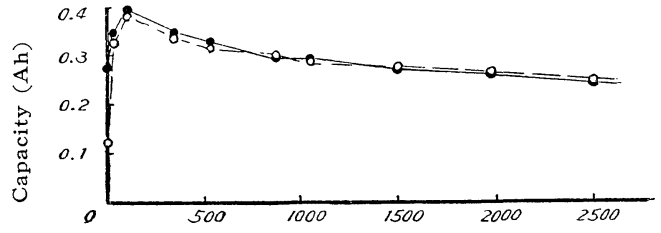

Number of cycles $(0.75$ A-15 min. Charge. 0.50 A-15 min. discharge)

Fig. 2 Results on the cycle test for the plates prepared by the most suitable procedure. other factors and so the putting in practice of the conclusion will not cause any serious errors.

On the other hand, as minor factors are liable to be affected mutually or by other factors, a conclusion: contrary to the fact may be obtained, but such an error in judgment will cause only a slight effect on the whole. An additional experiment by fixing larger factors at optimum conditions may be conducted. if necessary. In the present experiment, the quantity of additional iron salt and the temperature at which the precipitate is made, may be counted as minor factors. If an adequate precaution be taken, the orthogonal layout is sure to be a very powerful aid for these experiments.

In summary, 17 factors in the preparation of paste-type negative plate for alkaline storage battery have been tested by the two-step random combination method and the following conditions were found to be satisfactory: (1) Heating of the raw hydroxides at about $600^{\circ} \mathrm{C}$ for $30 \sim 60$ minutes, (2) Admixing of small amount of $\mathrm{HgO}$ and lignin, and (3) Covering the surface of the negative plate by alkaliproof materials such as saran.

Gratitudes are due to Mr. K. Araki of the Asahi Kasei Co., Ltd. who has supplied saran fabrics, and to Mr. G. Taguchi of this Laboratory who has contributed guidance to the planning of the experiment.

(Received July 27, 1957).

Literatures :

(1) K. Sugita : J. Electrochem. Soc. Japan, 24, 300 (1956).

(2) G. Taguchi : Determination of Common Difference, p. 67, JIS Association (1956). 